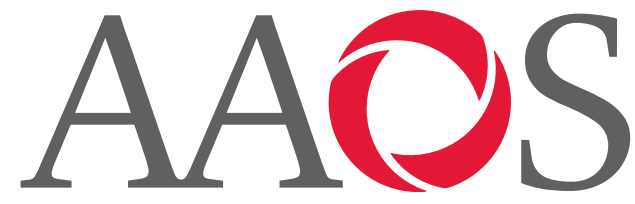

American Academy of Orthopaedic Surgeons

\title{
Selected
}

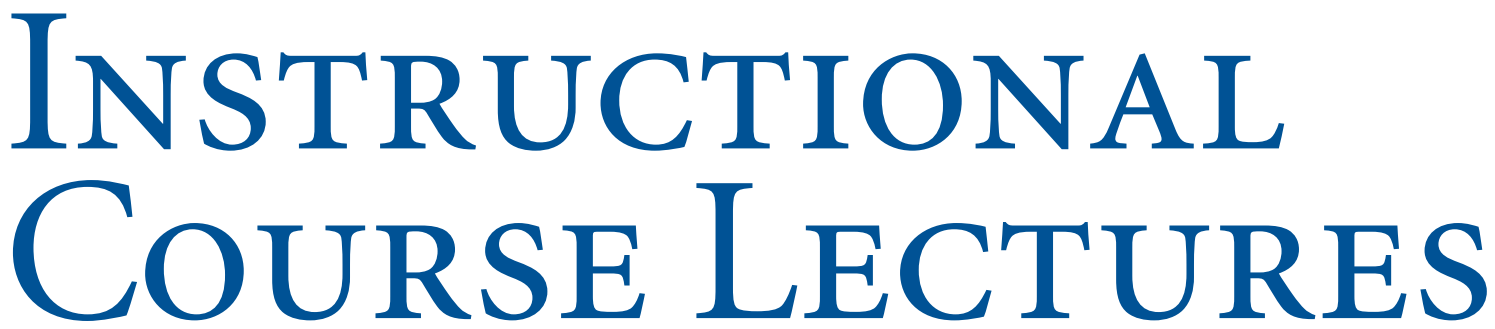

\section{The American Academy of Orthopaedic Surgeons}

\section{ROBERT A. HART}

EDITOR, VOL. 63

COMmitTeE

ROBERT A. HART

CHAIR

Craig J. Della Valle

Mark W. Pagnano

THOMAS W. THROCKMORTON

PaUl TORNETTA III

\section{EX-OFFICIO}

DEMPSEY S. SPRINGFIELD

DEPUTY EDITOR OF THE JOURNAL OF BONE AND JOINT SURGERY

FOR INSTRUCTIONAL COURSE LECTURES

Printed with permission of the American Academy of Orthopaedic Surgeons. This article, as well as other lectures presented at the Academy's Annual Meeting, will be available in March 2014 in Instructional Course Lectures, Volume 63. The complete volume can be ordered online at www.aaos.org, or by calling 800-626-6726 (8 A.M.-5 P.M., Central time). 


\title{
Diagnosis and Management of Developmental Dysplasia of the Hip from Triradiate Closure Through Young Adulthood
}

\author{
Klaus A. Siebenrock, MD, Simon D. Steppacher, MD, Christoph E. Albers, MD, Pascal C. Haefeli, MD, and Moritz Tannast, MD
}

An Instructional Course Lecture, American Academy of Orthopaedic Surgeons

Management of the Acetabular Side Closure of the triradiate cartilage may occur as early as eight to ten years of age $^{1}$. Thus, typically the pelvis of a very young teenager already is amenable to different kinds of juxta-acetabular osteotomies for the treatment of hip disorders. Treatment options for the dysplastic acetabulum can be divided into (1) augmentation and (2) reorientation procedures. Augmentation procedures include a Chiari osteotomy ${ }^{2}$ or different techniques of shelf procedures ${ }^{3}$, based on the principle of load reduction by distributing load through a larger surface area. However, the potentially damaged labrum and articular cartilage at the abnormally loaded acetabular rim ${ }^{4}$ remain within the main weight-bearing zone with both of these surgical procedures. This may be one main cause of inferior results reported with Chiari osteotomies in adolescents who are more than fourteen years old $^{5}$ or in patients with a torn labrum 6 . Augmentation procedures are not commonly indicated in adolescents and young adults currently, but may be considered in acetabula with a very short roof or in hips in which the acetabular radius is smaller than the radius of the femoral head.

Three types of juxta-acetabular osteotomies for acetabular reorientation are currently in wider use. These osteotomies include (1) a spherical or rotational osteotomy, (2) a triple osteotomy, and (3) the Bernese periacetabular osteotomy. The principle of the spherical or rotational osteotomy was described by Wagner ${ }^{7}$ in Europe and by Ninomiya and Tagawa ${ }^{8}$ in Japan. The osteotomy is performed with a curved chisel close to the subchondral bone. The advantage is that it provides a mobile fragment. However, this osteotomy lacks the potential for medialization of the hip center $^{9}$ and may become intra-articular in the caudal portion of the acetabu$\operatorname{lum}^{10}$. Tönnis et al. ${ }^{11}$ popularized a triple osteotomy with complete osteotomies of the iliac, ischial, and pubic bone. Initial fixation included osteosynthesis of the iliac and pubic bone. The recommended postoperative treatment was immobilization in a spica cast for several weeks. With the current technique, the ischial spine with the attached sacrospinal ligament remains attached to the pelvic segment, and fixation of the acetabular fragment has become easier without the need for postoperative cast immobilization. The Bernese periacetabular osteotomy was popularized in 1988 by Ganz et al. ${ }^{12}$ and was first performed in 1984. This osteotomy has the advantage of creating a polygonal acetabular fragment while leaving the posterior column intact, by an incomplete osteotomy of the ischium. There is immediate postoperative stability since the pelvic ring is not disrupted. There is no deformity of the true pelvis in young female patients, allowing for childbirth through vaginal delivery after surgical correction ${ }^{13}$. The mobile acetabular fragment allows adequate corrections, even for severe deformities, and has the potential for an optimal medialization of the acetabular center of rotation. Fixation of the

Disclosure: None of the authors received payments or services, either directly or indirectly (i.e., via his or her institution), from a third party in support of any aspect of this work. None of the authors, or their institution(s), have had any financial relationship, in the thirty-six months prior to submission of this work, with any entity in the biomedical arena that could be perceived to influence or have the potential to influence what is written in this work. Also, no author has had any other relationships, or has engaged in any other activities, that could be perceived to influence or have the potential to influence what is written in this work. The complete Disclosures of Potential Conflicts of Interest submitted by authors are always provided with the online version of the article. 

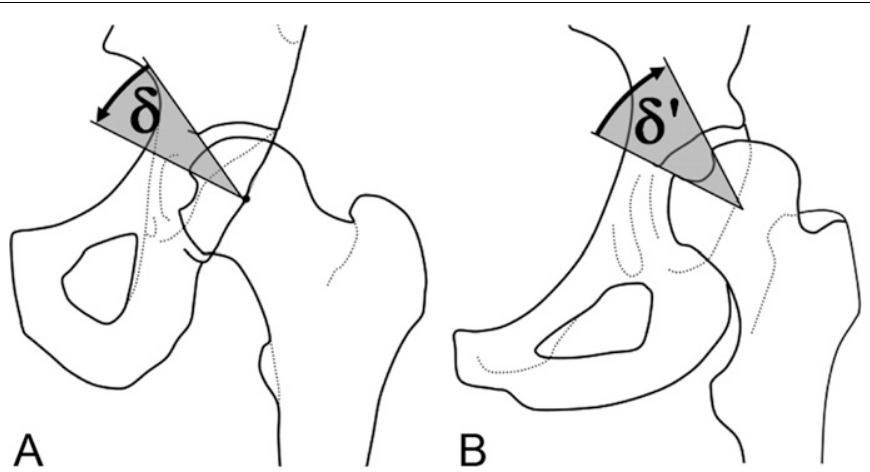

Fig. 1

Fig. 1-A In a normal hip, the fovea capitis femoris is caudal to the weight-bearing area of the acetabulum. Fig. 1-B In dysplastic hips, because of the extreme valgus, the fovea can extend into the weight-bearing area, reducing the loaded articular cartilage surface. The fovea-acetabular angle is defined as the angle formed by a line from the femoral head center to the medial edge of the weight-bearing zone of the acetabulum (reference line) and a line from the femoral head center to the superior edge of the fovea capitis femoris. The value of the fovea-acetabular angle is positive if the superior edge of the fovea capitis femoris lies caudal to the medial edge of the weight-bearing zone of the acetabulum (Fig. 1-A). It becomes negative if the superior edge of the fovea capitis femoris lies cranial to the medial edge of the weight-bearing zone of the acetabulum (Fig. 1-B).

osteotomized fragment can be done typically with screws only in the acetabular fragment, and postoperative care requires only partial weight-bearing on crutches without the need for a cast. Thus, the Bernese periacetabular osteotomy has become our preferred treatment for correction of acetabular dysplasia in hips with a closed triradiate growth plate.

\section{Treatment of the Abnormal \\ Femoral Side}

Developmental dysplasia of the hip also affects the femoral head side. There is a wide range of deformities of the proximal part of the femur from a subtle ovalshaped deformity of the femoral head to aberrant torsion or orientation of the femoral neck, to more severe abnormalities of the entire proximal part of the femur ${ }^{14-16}$.

\section{Additional Intertrochanteric Osteotomy} Generally, a concomitant intertrochanteric osteotomy is only indicated in approximately $10 \%$ of all patients undergoing periacetabular osteotomy ${ }^{17}$. The most common indications for an additional intertrochanteric osteotomy are (1) an extreme valgus angulation of the femoral neck with a fovea alta, (2) joint incongruency following acetabular reorientation (typically seen with more severe femoral head deformities), and (3) restoration of a normal femoral neck-shaft angle after a previous varus osteotomy of the proximal part of the femur.

\section{Extreme Valgus with Fovea Alta} In dysplastic hips, an abnormal valgus femoral neck configuration may be associated with a fovea $\operatorname{alta}^{18}$, with the fovea capitis femoris more cranial than in a normal hip joint and the ligamentum capitis femoris articulating with the weight-bearing area of the acetabular cartilage (Figs. 1-A and 1-B). A fovea alta further reduces the weight-bearing zone between the cartilaginous joint surfaces of the femoral head and the acetabulum, aggravating the underlying dysplastic pathomorphology ${ }^{18}$.

\section{Joint Incongruency After \\ Periacetabular Osteotomy}

Primary or secondary deformity of the femoral head leads to numerous instantaneous centers of rotation that depend on the actual surface under stress, which varies with the relative position of the acetabulum and femur ${ }^{17}$. This can be seen on an abduction radiograph made either preoperatively or intraoperatively after periacetabular osteotomy. If the abduction radiograph shows improved hip congruency, a varus osteotomy should be considered (Figs. 2-A, 2-B, and 2-C $)^{17}$.

\section{Femoral Neck-Shaft Realignment} After a Previous Proximal Femoral Varus Osteotomy

If residual hip dysplasia after a previous proximal femoral varus osteotomy needs acetabular correction, a periacetabular osteotomy may lead to restricted hip abduction, flexion, and internal rotation. A corrective rotational valgus intertrochanteric osteotomy can then minimize anterolateral 


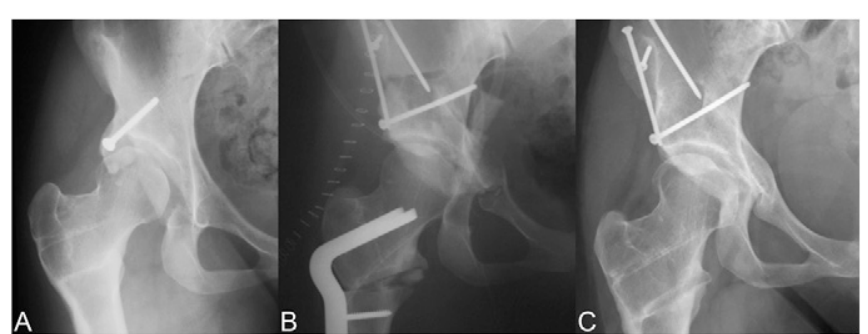

Fig. 3

Figs. 3-A, 3-B, and 3-C A twenty-four-year-old man with residual dysplasia after previous shelf acetabuloplasty and varus femoral osteotomy of the right hip. Fig. 3-A Preoperative anteroposterior radiograph. Fig. 3-B Anteroposterior radiograph made after a periacetabular osteotomy was performed with resection of the shelf acetabuloplasty and a concomitant intertrochanteric valgus femoral osteotomy. Fig. 3-C Radiograph of the hip made ten years postoperatively showing an excellent clinical result.

impingement and improve clinical abduction by advancing the greater trochanter distally and laterally (Figs. 3-A, 3-B, and 3-C).

\section{Substantial (Perthes-Like) Femoral Head Deformities}

Surgical correction of acetabular abnormalities associated with major femoral head deformities is complex. It is conceivable that hips with major femoral head deformities, such as Legg-CalvéPerthes disease or slipped capital femoral epiphysis, should be treated with additional correction of the deformity of the proximal part of the femur. In severely deformed femoral heads, the femoral side needs to be addressed prior to the periacetabular osteotomy, at times with the technique of a surgical hip dislocation with or without an extended retinacular soft-tissue flap ${ }^{19}$. Surgical correction includes osteoplasty of the severely deformed femoral head, trimming of the greater trochanter, and relative lengthening of the femoral neck with distalization of the greater trochanter (see Appendix). In some patients, intertrochanteric flexion or extension osteotomies can be performed.

\section{Prevention of Femoroacetabular Impingement}

Hips with developmental dysplasia often have a decreased femoral head-neck offset $^{14}$. With the acetabular reorientation typically anterosuperior, head coverage will be increased, which potentially initiates painful femoroacetab- ular impingement against the proximal part of the femur with reduced femoral head-neck offset (Fig. 4). Therefore, in hips with limited internal rotation $\left(<30^{\circ}\right)$, the joint should be opened, visually inspected, and analyzed for impingement with the hip flexed and internally rotated ${ }^{20}$. The arthrotomy allows for inspection of the acetabular labrum as well as the assessment of the anatomy of the femoral head-neck junction. An osteochondroplasty with removal of the aspherical portion of the femoral head-neck junction should be done (Fig. 4 and Appendix). To provide a rough guideline for the amount of bone to be resected, the goal of internal rotation of $30^{\circ}$ in $90^{\circ}$ of flexion seems appropriate $^{21}$. Optionally, major unstable labral tears can be debrided or repaired with suture anchors ${ }^{15}$.

\section{Surgical Considerations and Our Preferred Technique}

The patient is placed in a supine position with the hemipelvis and leg of the affected side sterilely prepared and draped. The skin incision is a shortened ilioinguinal incision. The incision starts laterally at the intersection between the medial and middle third of the iliac wing and extends about $5 \mathrm{~cm}$ medial to the anterior superior iliac spine. The incision is placed about $2 \mathrm{~cm}$ distal to the iliac crest (Fig. 5-A). This type of incision is cosmetically superior to the modified Smith-Petersen incision. The sartorius muscle (medial) is separated from the tensor fascia lata muscle (lateral), exposing the direct origin of the rectus femoris muscle from the anterior inferior iliac spine. The abdominal wall muscles are sharply dissected off the iliac crest, and the iliac muscle is mobilized from the iliac wing. The origin of the sartorius muscle together with the inguinal ligament is sharply dissected, mobilized, and medially retracted from the anterior superior iliac spine with the 


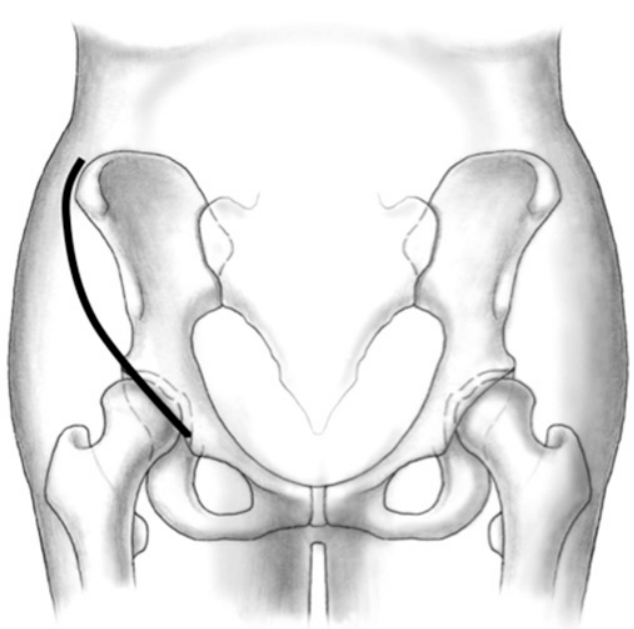

A

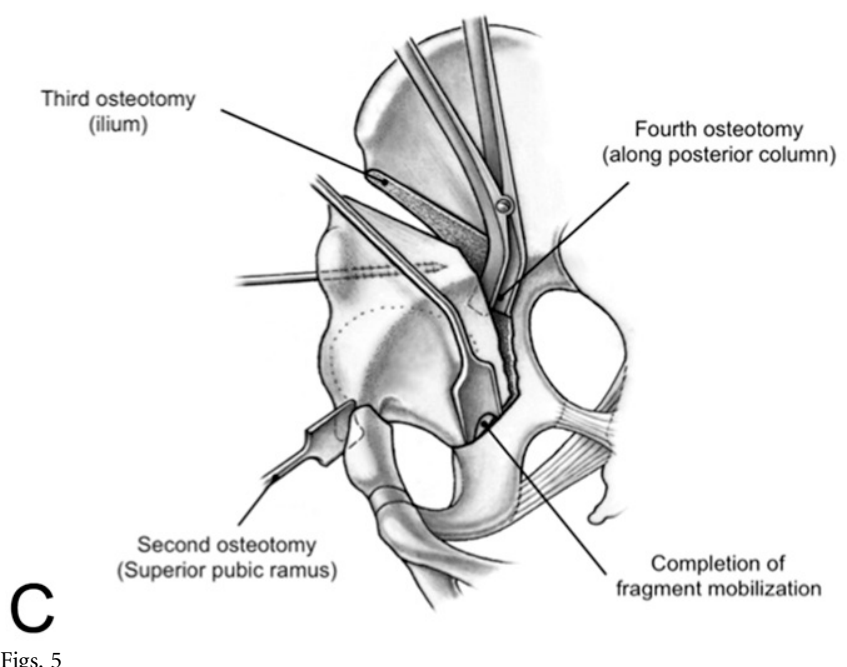

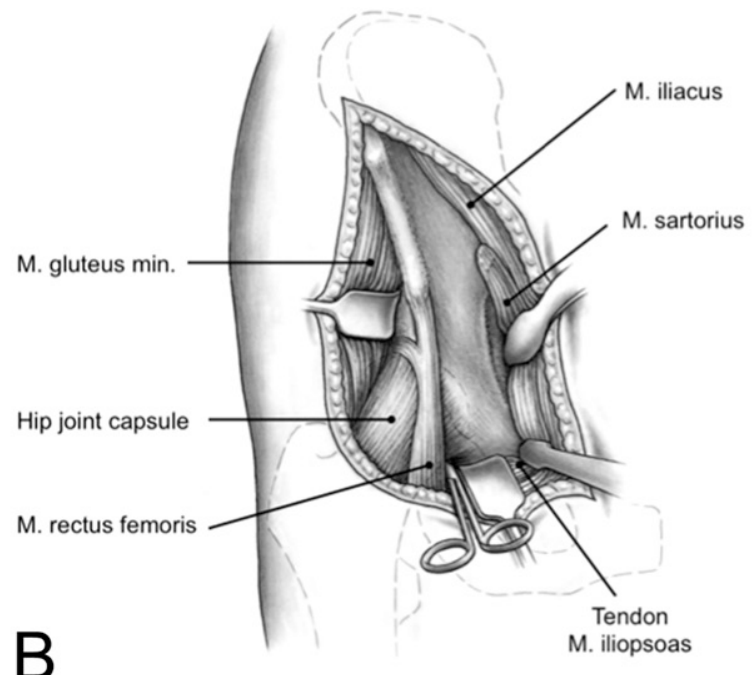

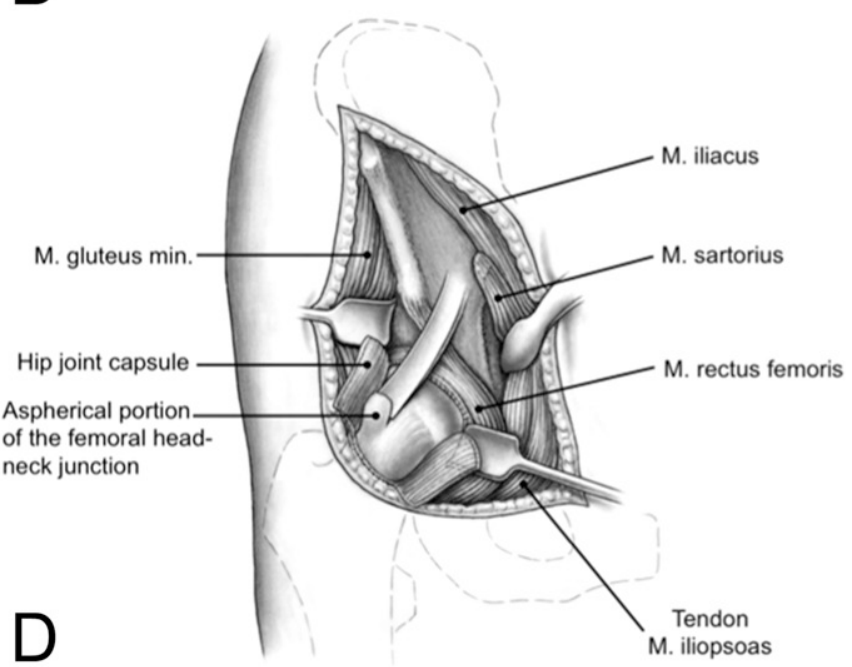

Figs. 5-A through 5-D Our preferred technique of periacetabular osteotomy is shown. Fig. 5-A An ilioinguinal incision is performed. Fig. 5-B Intraoperative view after mobilization of the iliopsoas and the sartorius muscles. The first cut of the ischium is performed through the interval between the joint capsule and the rectus femoris muscle. Fig. 5-C The four periacetabular osteotomies are shown. Fig. 5-D Offset creation is performed with the rectus femoris muscle retracted medially through an $\mathrm{H}$-shaped capsulotomy.

iliacus and psoas muscles (Fig. 5-B). As a further modification from the previously used technique, the two origins of the rectus femoris muscle are left intact and the interval between the rectus muscle (lateral) and the iliopsoas muscle (medial) is dissected and bluntly opened with scissors. The iliocapsularis muscle ${ }^{22}$ is sharply separated from the capsule laterally and mobilized medially, together with the iliopsoas muscle. A Hohmann retractor is placed into the superior pubic ramus 2 to $3 \mathrm{~cm}$ medial to the pubic eminence. With use of scissors, the infra-articular space is spread open strictly following the con- tour of the calcar directly on the intact capsule (Fig. 5-B). With the tip of the scissors, the ischial bone can be palpated beneath the posterior horn. With a specially designed curved chisel, the first ischial osteotomy is done. The osteotomy of approximately 4 to $5 \mathrm{~cm}$ is an incomplete cut of the ischium. Next, two blunt retractors are placed around the superior aspect of the pubic bone to protect the soft tissues and perform the pubic osteotomy (Fig. 5-C). At the level of the anterior superior iliac spine, partial elevation of the abductor muscles from the outside of the iliac wing is done to place a blunt retractor for protection of the abductor muscles. The periosteum and obturator internus muscles are bluntly dissected off the quadrilateral plate, and another blunt curved retractor is placed on the quadrilateral surface close to the ischial spine to further retract the soft tissues medially. With use of an oscillating saw, an oblique iliac osteotomy is performed at the level of the anterior superior iliac spine (Fig. 5-C). This osteotomy ends 1 to $2 \mathrm{~cm}$ lateral to the pelvic rim. From there, an osteotomy angled approximately $110^{\circ}$ distally in regard to the previous horizontal cut of the ilium. This osteotomy is performed with a 
TABLE I Minimum Ten-Year Survivorship of the Hip After Surgical Treatment of Developmental Dysplasia with Conversion to Total Hip Arthroplasty as the End Point

\begin{tabular}{|c|c|c|c|c|c|}
\hline Kralj et al. ${ }^{27}$ (2005) & Periacetabular & $12(7-15)$ & 26 & $34(18-50)$ & 85 \\
\hline Steppacher et al. ${ }^{26}$ (2008) & Periacetabular & $20.4(19-23)$ & 75 & $29.3(13-56)$ & 61 \\
\hline Matheney et al. ${ }^{40}$ (2009) & Periacetabular & $9 \pm 2.2$ & 135 & $23(10-44)$ & 84 \\
\hline Nakamura et al. ${ }^{34}$ (1998) & Rotational & $13(10-23)$ & 145 & $28(11-52)$ & 95 \\
\hline Takatori et al. ${ }^{47}$ (2000) & Rotational & $13(10-18)$ & 28 & $33(19-40)$ & 96 \\
\hline Takatori et al. ${ }^{30}$ (2001) & Rotational & $19.8(15-22)$ & 15 & $24.3(20-28)$ & 100 \\
\hline Nozawa et al. ${ }^{48}$ (2002) & Rotational & $11.4(10-15)$ & 50 & $31.8(13-53)$ & 98 \\
\hline Yasunaga et al. ${ }^{39}$ (2004) & Rotational & $11(8-15)$ & 61 & $35(13-58)$ & 100 \\
\hline Schramm et al. ${ }^{9}$ (2003) & Wagner spherical & $23.9(20-29)$ & 22 & $24.4 \pm 9.7$ & 68 \\
\hline Zagra et al. $^{29}$ (2007) & Wagner spherical & $23.1(21-27)$ & 10 & $19.3(17-27)$ & 100 \\
\hline
\end{tabular}

*Continuous data are expressed as the mean, with the range in parentheses if available, or the standard deviation.

straight and a curved chisel and is directed to the ischial spine. A Schanz screw is inserted at the level of the anterior inferior iliac spine to do a controlled fracture of the remaining bone (Fig. 5-C). A spreader inserted in the osteotomy gap of the iliac bone assists this maneuver. The controlled fracture can be aided by an additional cut with the specially designed curved chisel from the inside of the quadrilateral surface. Once the fragment is completely free, the acetabulum is oriented with the Schanz screw and Hohmann retractors. Preliminary fixation of the bone is done with use of $2.5-\mathrm{mm}$ partially threaded pins.

An intraoperative radiograph is made with a radiographic plate slid underneath the patient, using a specially designed "sandwich" table, which eliminates the need to move the patient or the drapes. The evaluation criteria for an optimal correction are described in more detail in the following section. The intraoperative decision for the need of an additional osteotomy on the femoral side may require additional abduction or adduction radiographs. Three $3.5-\mathrm{mm}$ cortical screws are typically used to definitively fix the acetabular fragment. Internal rotation is evaluated with the hip flexed $90^{\circ}$. If there is $<30^{\circ}$ of internal rotation in the presence of decreased femoral head-neck offset on a lateral radiograph, an $\mathrm{H}$-shaped capsulotomy is performed (Fig. 5-D).

The rectus femoris muscle is retracted medially for the capsulotomy. The osseous contour of the anterosuperior femoral head-neck contour ${ }^{20}$ is trimmed (a so-called offset correction) with a curved chisel and/or a high-speed burr (Fig. 5-D) ${ }^{20}$. This is best performed with the lower limb in $10^{\circ}$ of flexion and various positions of rotation. The incision is closed with absorbable sutures, and a running suture is placed along the iliac crest to reattach the muscle sleeve and the inguinal ligament to the outer fascia of the pelvis and thigh. Postoperatively, a continuous passive motion machine is used and partial weightbearing of 15 to $20 \mathrm{~kg}$ is recommended for six to eight weeks after surgery.

\section{Intraoperative Evaluation}

Intraoperative evaluation can most accurately and efficiently be done by examining an anteroposterior pelvic radiograph. The tube-to-film distance is approximately $1.2 \mathrm{~m}$ in our department. Recommendations for defining the so-called ideal correction parameters can only be given in ranges and not to the exact degree. The parameters and recommended goals are (1) a lateral center-edge angle between $20^{\circ}$ and $35^{\circ}$, preferably between $25^{\circ}$ and $30^{\circ}$; (2) an anterior center-edge angle between $0^{\circ}$ and $10^{\circ}$, preferably in the upper range; (3) head medialization with a distance between the medial aspect of the femoral head and the ilioischial line of $<10 \mathrm{~mm}$; (4) restoration of the Shenton line; (5) a weight-bearing dome centered over the head; (6) anteversion of the acetabulum as defined by the absence of a cross-over sign and the outlines of the anterior and posterior rim meeting at the lateral acetabular edge; and (7) restoration of hip joint congruency ${ }^{23}$.

Persistent joint incongruity after acetabular reorientation requires intraoperative functional radiographs made with the hip in abduction or adduction to decide whether an intertrochanteric osteotomy is necessary. After obtaining a satisfactory correction, we judge the hip 
motion, especially flexion and internal rotation. Although there is no agreement regarding the definition of decreased internal rotation, internal rotation that is only between $15^{\circ}$ and $30^{\circ}$ should lead one to further search for its cause. Exclusion of intra-articular femoroacetabular impingement or extra-articular impingement against the anterior inferior iliac spine is recommended ${ }^{24}$. In a recent series of ninety patients, a femoral head-neck offset correction was performed in $57 \%$ of the hips after acetabular reorientation through a periacetabular osteotomy ${ }^{25}$.

\section{Review of the Literature}

There is evidence that acetabular reorientation can decelerate joint degeneration $^{26}$. The long-term results (ten to almost thirty years) for all three types of juxta-acetabular osteotomies are summarized in Table I. The survivorship of the hip has been reproducibly shown to be approximately $90 \%$ after ten years and $60 \%$ to $70 \%$ after twenty years, independent of the reorientation technique. The long-term reports of the early series typically involved heterogeneous patient cohorts ${ }^{26-28}$, including patients with advanced age and/or joint degeneration. In a follow-up study with a more homogeneous patient cohort at our institution, a good clinical result without progression of osteoarthritis was achieved in $90 \%$ of the patients at a minimum ten-year follow-up interval ${ }^{25}$. Follow-up studies that have shown survivorship of up to $100 \%$ typically have involved a nonconsecutive series of patients ${ }^{29}$, exclusive of patients with previous surgical procedures on the hip $^{30}$, low numbers of patients ${ }^{29-31}$, or a substantial percentage of patients lost to follow-up ${ }^{30}$. The natural history of hip dysplasia is not as good ${ }^{32}$.

Several common negative predictors influencing the long-term outcome after acetabular reorientation for devel- opmental dysplasia of the hip were identified. These include mainly demographic or independent preoperative factors such as advanced age $e^{27,33,34}$, low preoperative functional hip scores ${ }^{26,35}$, a body mass index of $>25\left(\mathrm{~kg} / \mathrm{m}^{2}\right)^{36}$, preexisting early osteoarthritis ${ }^{26,37-41}$, a preoperative limp ${ }^{26}$, evidence of a labral tear $^{42}$ with pain in flexion and internal rotation $^{26}$, and preoperative femoral head subluxation ${ }^{25,41}$.

Postoperative lateral acetabular undercoverage ${ }^{25,43}$ and excessive acetabular anteversion ${ }^{25}$ can lead to persistent static overload of the lateral and/or the anterior acetabular rim with subsequent degeneration. Postoperative lateral overcoverage $e^{20,25}$ and acetabular retroversion $^{25,44}$ have been associated with decreased hip survivorship because of iatrogenic postoperative femoroacetabular impingement between the overcorrected acetabulum and the proximal part of the femur. A previous femoral head-neck offset correction or, if necessary, an intraoperative offset correction in hips with an aspherical head-neck junction improves the ten-year survivorship ${ }^{25,45}$. In conclusion, improper acetabular reorientation, specifically incorrect acetabular version and a concomitant persistence of an aspherical femoral head-neck junction, needs to be included as a risk factor for a less favorable outcome ${ }^{25}$.

\section{Overview}

The appropriate surgical treatment of hip dysplasia after closure of the triradiate cartilage is a reorientation of the entire acetabulum. Among the different surgical techniques for acetabular reorientation, periacetabular osteotomy has become the gold standard. It provides the largest reorientation potential with inherent stability because of its polygonal shape without changing the dimensions of the birth canal. There is increasing evidence that the natural degeneration in dysplastic hips can be decelerated by periacetabular osteotomy. The survival rate of the hip after acetabular reorientation is approximately $90 \%$ after ten years and $60 \%$ to $70 \%$ after twenty years. Careful patient selection, an optimal acetabular reorientation, and a concomitant osteochondroplasty of an aspherical femoral head-neck junction may lead to improved long-term results.

\section{Appendix}

eA Figures showing radiographs of a eA twenty-five-year-old woman with residual deformity from Legg-CalvéPerthes disease who had an excellent result after a periacetabular osteotomy, surgical hip dislocation with trimming of the femoral head-neck junction, and lengthening of the femoral neck as well as radiographs of a female patient with developmental dysplasia of the hip who had correction of a decreased femoral head-neck offset with an arthrotomy are available with the online version of this article as a data supplement at jbjs.org.

Note: The authors thank Joseph M. Schwab, MD, for assistance in the preparation of this manuscript.

Klaus A. Siebenrock, MD

Simon D. Steppacher, MD

Christoph E. Albers, MD

Pascal C. Haefeli, MD

Moritz Tannast, MD

Department of Orthopaedic Surgery, Inselspital, Bern University Hospital, Freiburgstrasse, Bern 3010, Switzerland

Printed with permission of the American Academy of Orthopaedic Surgeons. This article, as well as other lectures presented at the Academy's Annual Meeting, will be available in March 2014 in Instructional Course Lectures, Volume 63. The complete volume can be ordered online at www.aaos.org, or by calling 800-626-6726 (8 a.m.-5 p.m., Central time).

\section{References}

1. Trousdale RT, Ganz R. Posttraumatic acetabular dysplasia. Clin Orthop Relat Res. 1994 Aug;(305):124-32.

2. Chiari K. [Pelvic osteotomy in hip arthroplasty]. Wien Med Wochenschr. 1953 Sep 19;103(38): 707-9. German.
3. Lance M. Consitution d'une butrée ostéoplastique dans les luxationes subluxations congénitales de la hanche. Presse Med. 1925;33:945-58. French. 4. Klaue K, Durnin CW, Ganz R. The acetabular rim syndrome. A clinical presentation of dysplasia of the hip. J Bone Joint Surg Br. 1991 May;73(3):423-9.
5. Windhager R, Pongracz N, Schönecker W, Kotz R. Chiari osteotomy for congenital dislocation and subluxation of the hip. Results after 20 to 34 years follow-up. J Bone Joint Surg Br. 1991 Nov;73(6):890-5.

6. Nishina T, Saito S, Ohzono K, Shimizu N, Hosoya T, Ono K. Chiari pelvic osteotomy for osteoarthritis. The 
influence of the torn and detached acetabular labrum. J Bone Joint Surg Br. 1990 Sep;72(5):765-9.

7. Wagner H. Osteotomies for congenital hip dislocation. In: The hip. Proceedings of the fourth open scientific meeting of the hip society. St. Louis: CV Mosby; 1976. p 45-66.

8. Ninomiya S, Tagawa H. Rotational acetabular osteotomy for the dysplastic hip. J Bone Joint Surg Am. 1984 Mar;66(3):430-6.

9. Schramm M, Hohmann D, Radespiel-Troger M, Pitto RP. Treatment of the dysplastic acetabulum with Wagner spherical osteotomy. A study of patients followed for a minimum of twenty years. J Bone Joint Surg Am. 2003 May;85(5):808-14.

10. Siebenrock KA, Schöll E, Lottenbach M, Ganz R. Bernese periacetabular osteotomy. Clin Orthop Relat Res. 1999 Jun;(363):9-20.

11. Tönnis D, Behrens $K$, Tscharani F. A modified technique of the triple pelvic osteotomy: early results. J Pediatr Orthop. 1981;1(3):241-9.

12. Ganz R, Klaue K, Vinh TS, Mast JW. A new periacetabular osteotomy for the treatment of hip dysplasias. Technique and preliminary results. Clin Orthop Relat Res. 1988 Jul;(232):26-36.

13. Leunig M, Siebenrock KA, Ganz R. Rationale of periacetabular osteotomy and background work. Instr Course Lect. 2001:50:229-38.

14. Steppacher SD, Tannast M, Werlen S, Siebenrock KA. Femoral morphology differs between deficient and excessive acetabular coverage. Clin Orthop Relat Res. 2008 Apr;466(4):782-90.

15. Clohisy JC, Barrett SE, Gordon JE, Delgado ED, Schoenecker PL. Periacetabular osteotomy in the treatment of severe acetabular dysplasia. Surgical technique. J Bone Joint Surg Am. 2006 Mar;88(Suppl 1 Pt 1):65-83.

16. Tannast M, Hanke M, Ecker TM, Murphy SB, Albers CE, Puls M. LCPD: reduced range of motion resulting from extra- and intraarticular impingement. Clin Orthop Relat Res. 2012 Sep;470(9):2431-40. 17. Hersche 0 , Casillas M, Ganz R. Indications for intertrochanteric osteotomy after periacetabular osteotomy for adult hip dysplasia. Clin Orthop Relat Res. 1998 Feb;(347):19-26.

18. Nötzli HP, Müller SM, Ganz R. [The relationship between fovea capitis femoris and weight bearing area in the normal and dysplastic hip in adults: a radiologic study]. Z Orthop Ihre Grenzgeb. 2001 NovDec;139(6):502-6. German.

19. Ganz R, Huff TW, Leunig M. Extended retinacular soft-tissue flap for intra-articular hip surgery: surgical technique, indications, and results of application. Instr Course Lect. 2009;58:241-55.

20. Myers SR, Eijer H, Ganz R. Anterior femoroacetabular impingement after periacetabular osteotomy. Clin Orthop Relat Res. 1999 Jun;(363):93-9.

21. Siebenrock KA, Schoeniger R, Ganz R. Anterior femoro-acetabular impingement due to acetabular retroversion. Treatment with periacetabular osteotomy. J Bone Joint Surg Am. 2003 Feb;85(2):278-86.
22. Babst D, Steppacher SD, Ganz R, Siebenrock KA, Tannast M. The iliocapsularis muscle: an important stabilizer in the dysplastic hip. Clin Orthop Relat Res. 2011 Jun;469(6):1728-34.

23. Millis MB, Siebenrock KA; Session Participants. Report of breakout session: Defining parameters for correcting the acetabulum during a pelvic reorientation osteotomy. Clin Orthop Relat Res. 2012 Dec;470(12):3453-5.

24. Ziebarth K, Balakumar J, Domayer S, Kim YJ, Millis MB. Bernese periacetabular osteotomy in males: is there an increased risk of femoroacetabular impingement (FAl) after Bernese periacetabular osteotomy? Clin Orthop Relat Res. 2011 Feb;469(2): 447-53.

25. Albers CE, Steppacher SD, Ganz R, Tannast M, Siebenrock KA. Impingement adversely impacts 10 year survivorship after periacetabular osteotomy. Clin Orthop Relat Res. [In press]

26. Steppacher SD, Tannast M, Ganz R, Siebenrock KA. Mean 20-year followup of Bernese periacetabular osteotomy. Clin Orthop Relat Res. $2008 \mathrm{Jul} ; 466(7)$ : 1633-44.

27. Kralj M, Mavcic B, Antolic V, Iglic A, Kralj-lglic V. The Bernese periacetabular osteotomy: clinical, radiographic and mechanical 7-15-year follow-up of 26 hips. Acta Orthop. 2005 Dec;76(6):833-40.

28. Flecher X, Casiraghi A, Aubaniac JM, Argenson JN. [Periacetabular osteotomy medium term survival in adult acetabular dysplasia]. Rev Chir Orthop Reparatrice Appar Mot. 2008 Jun;94(4):336-45. French.

29. Zagra L, Corbella M, Giacometti Ceroni R. Wagner's spherical periacetabular osteotomy: long term results. Hip Int. 2007;17(Suppl 5):S65-71. 30. Takatori Y, Ninomiya S, Nakamura S, Morimoto S, Moro T, Nagai I, Mabuchi A. Long-term results of rotational acetabular osteotomy in patients with slight narrowing of the joint space on preoperative radiographic findings. J Orthop Sci. 2001;6(2):137-40. 31. Guille JT, Forlin E, Kumar SJ, MacEwen GD. Triple osteotomy of the innominate bone in treatment of developmental dysplasia of the hip. J Pediatr Orthop. 1992 Nov-Dec;12(6):718-21.

32. Murphy SB, Ganz R, Müller ME. The prognosis in untreated dysplasia of the hip. A study of radiographic factors that predict the outcome. J Bone Joint Surg Am. 1995 Jul;77(7):985-9.

33. Murphy S, Deshmukh R. Periacetabular osteotomy: preoperative radiographic predictors of outcome. Clin Orthop Relat Res. 2002 Dec;(405): 168-74.

34. Nakamura S, Ninomiya S, Takatori Y, Morimoto $\mathrm{S}$, Umeyama T. Long-term outcome of rotational acetabular osteotomy: 145 hips followed for 10-23 years. Acta Orthop Scand. 1998 Jun;69(3):259-65. 35. van Hellemondt GG, Sonneveld $H$, Schreuder MH, Kooijman MA, de Kleuver M. Triple osteotomy of the pelvis for acetabular dysplasia: results at a mean follow-up of 15 years. J Bone Joint Surg Br. 2005 Jul;87(7):911-5.

36. Janssen D, Kalchschmidt K, Katthagen BD. Triple pelvic osteotomy as treatment for osteoarthritis secondary to developmental dysplasia of the hip. Int Orthop. 2009 Dec;33(6):1555-9.

37. de Kleuver M, Kooijman MA, Pavlov PW, Veth RP. Triple osteotomy of the pelvis for acetabular dysplasia: results at 8 to 15 years. J Bone Joint Surg Br. 1997 Mar;79(2):225-9.

38. Trousdale RT, Ekkernkamp A, Ganz R, Wallrichs SL. Periacetabular and intertrochanteric osteotomy for the treatment of osteoarthrosis in dysplastic hips. J Bone Joint Surg Am. 1995 Jan;77(1):73-85.

39. Yasunaga $Y$, Ochi M, Shimogaki K, Yamamoto $S$, Iwamori H. Rotational acetabular osteotomy for hip dysplasia: 61 hips followed for 8-15 years. Acta Orthop Scand. 2004 Feb;75(1):10-5.

40. Matheney T, Kim YJ, Zurakowski D, Matero C, Millis M. Intermediate to long-term results following the Bernese periacetabular osteotomy and predictors of clinical outcome. J Bone Joint Surg Am. 2009 Sep;91(9):2113-23.

41. Cunningham $T$, Jessel $R$, Zurakowski $D$, Millis MB, Kim YJ. Delayed gadolinium-enhanced magnetic resonance imaging of cartilage to predict early failure of Bernese periacetabular osteotomy for hip dysplasia. J Bone Joint Surg Am. 2006 Jul;88(7):1540-8.

42. Jessel RH, Zurakowski D, Zilkens C, Burstein D, Gray ML, Kim YJ. Radiographic and patient factors associated with pre-radiographic osteoarthritis in hip dysplasia. J Bone Joint Surg Am. 2009

May;91(5):1120-9.

43. Sakai T, Nishii T, Takao M, Ohzono K, Sugano $\mathrm{N}$. High survival of dome pelvic osteotomy in patients with early osteoarthritis from hip dysplasia. Clin Orthop Relat Res. 2012 Sep;470(9):2573-82.

44. Yasunaga $Y$, Yamasaki $T$, Matsuo $T$, Ishikawa $M$, Adachi N, Ochi M. Crossover sign after rotational acetabular osteotomy for dysplasia of the hip. J Orthop Sci. 2010 Jul;15(4):463-9.

45. Ohashi $\mathrm{H}$, Hirohashi K, Yamano Y. Factors influencing the outcome of Chiari pelvic osteotomy: a long-term follow-up. J Bone Joint Surg Br. 2000 May;82(4):517-25

46. Ito $\mathrm{H}$, Tanino $\mathrm{H}$, Yamanaka $\mathrm{Y}$, Nakamura $\mathrm{T}$, Minami A, Matsuno T. The Chiari pelvic osteotomy for patients with dysplastic hips and poor joint congruency: long-term follow-up. J Bone Joint Surg Br. 2011 Jun;93(6):726-31.

47. Takatori $Y$, Ninomiya S, Nakamura S, Morimoto $\mathrm{S}$, Moro T, Nagai I. Long-term results of rotational acetabular osteotomy in young patients with advanced osteoarthrosis of the hip. J Orthop Sci. 2000;5(4):336-41.

48. Nozawa M, Shitoto K, Matsuda K, Maezawa K, Kurosawa $\mathrm{H}$. Rotational acetabular osteotomy for acetabular dysplasia. A follow-up for more than ten years. J Bone Joint Surg Br. 2002 Jan;84(1):59-65. 